\title{
Memoriais de formação e os percursos de construção do puzzle de pesquisa
}

\author{
Training memories and the construction routes of the research puzzle \\ Memorias de capacitación y rutas de construcción del rompecabezas de investigación
}

Recebido: 19/01/2021 | Revisado: 23/01/2021 | Aceito: 23/01/2021 | Publicado: 30/01/2021

\author{
Américo Junior Nunes da Silva \\ ORCID: https://orcid.org/0000-0002-7283-0367 \\ Universidade do Estado da Bahia, Brasil \\ E-mail: ajnunes@uneb.br
}

\begin{abstract}
Resumo
Este artigo é recorte de pesquisa de doutoramento e objetiva, exclusivamente para este texto, refletir sobre o que revelou as minhas escritas (auto)biográficas, em memoriais de formação construídos ao longo da vida, quanto ao constituir-se docente, formador de professores, pesquisador e os reflexos desses percursos da vida, pessoal e profissional, no constituir o puzzle de pesquisa. Nesse sentido, portanto, autores que discutem essa perspectiva de pesquisa fazem parte da fundamentação teórica, como por exemplo, Clandinin (2013), Clandinin \& Connely (2015), Josso (2007), Souza (2006), Benjamin (1996), Larrosa Bondía (2002), Roldão (2007), Flores (2014), D’Ambrosio (1998) e Passos (2010). Durante toda minha trajetória pessoal e profissional, como foi apresentado ao longo do artigo, me envolvi profundamente com as questões de ludicidade e formação de professores que ensinam(arão) Matemática. Tudo isso me aproximou do puzzle de pesquisa do doutoramento. Espero que esse texto possibilite a aproximação dos leitores com a pesquisa narrativa e que, mais estudos dessa natureza sejam construídos no Brasil.
\end{abstract}

Palavras-chave: Pesquisa; Narrativas; Experiência; Memoriais; (Auto)biografia.

\begin{abstract}
This article is an excerpt from doctoral research and aims, exclusively for that text, to reflect on what my (auto)biographical writings revealed, in training memorials built throughout life, as to becoming a teacher, teacher trainer, researcher and the reflections of these life paths, personal and professional, do not constitute the research puzzle. In this sense, therefore, authors who discuss this research perspective are part of the theoretical foundation, such as, for example, Clandinin (2013), Clandinin and Connely (2015), Josso (2007), Souza (2006), Benjamin (1996), Larrosa Bondía (2002), Roldão (2007), Flores (2014), D'Ambrosio (1998) and Passos (2010). Throughout my personal and professional trajectory, as it was presented throughout the article, I was deeply involved with the issues of playfulness and teacher training that teach (Aaron) mathematics. All of this brought me closer to the PhD research puzzle. I hope that this text will allow readers to get closer to narrative research and that more studies of this nature will be built in Brazil.
\end{abstract}

Keywords: Research; Narratives; Experience; Memorials; (Auto)biography.

\begin{abstract}
Resumen
Este artículo es un extracto de la investigación doctoral y tiene como objetivo, exclusivamente para ese texto, reflexionar sobre lo que mis escritos (auto)biográficos revelaron, en memoriales de capacitación construidos a lo largo de la vida, para convertirse en un maestro, un entrenador de maestros, investigador y las reflexiones de estos caminos de la vida, personal y profesional, no constituyen el rompecabezas de la investigación. En este sentido, por lo tanto, los autores que discuten esta perspectiva de investigación son parte de la base teórica, como, por ejemplo, Clandinin (2013), Clandinin y Connely (2015), Josso (2007), Souza (2006), Benjamin (1996), Larrosa Bondía (2002), Roldão (2007), Flores (2014), D'Ambrosio (1998) y Passos (2010). A lo largo de mi trayectoria personal y profesional, tal como se presentó a lo largo del artículo, estuve profundamente involucrado con los temas de la diversión y la capacitación docente que enseñan matemáticas (Aaron). Todo esto me acercó al rompecabezas de la investigación de doctorado. Espero que este texto permita a los lectores acercarse a la investigación narrativa y que se construyan más estudios de esta naturaleza en Brasil.
\end{abstract}

Palabras clave: Investigación; Narrativas; Experiencia; Memoriales; (Auto)biografía.

\section{Introdução}

Este artigo é um recorte de minha pesquisa de doutoramento ${ }^{1}$, no Programa de Pós-Graduação em Educação da

\footnotetext{
${ }^{1}$ A pesquisa foi intitulada: "Querido diário... o que revelam as narrativas sobre ludicidade, formação e futura prática do professor que ensina(rá) matemática nos anos iniciais”;
} 
Universidade Federal de São Carlos (UFSCar), e objetiva refletir sobre o que revelou as escritas (auto)biográficas, em meus memoriais de formação construídos ao longo da vida, quanto ao constituir-se docente, formador de professores, pesquisador e os reflexos desses percursos da vida, pessoal e profissional, no constituir o puzzle de pesquisa.

A pesquisa narrativa foi escolhida, tendo em vista o que objetivo e apresento no parágrafo anterior, enquanto método e fenômeno a ser estudado, por ter sido entendida, como sinalizam Clandinin e Connely (2000), enquanto uma das formas de compreender a experiência. Para mim, nesse momento, enquanto a melhor forma de compreender a experiência.

A experiência ${ }^{2}$, nesse momento, concordando com o que nos apresenta Larrosa Bondía (2002, p. 21), "é o que nos passa, o que nos aconteceu, o que nos toca. Não o que se passa, não o que acontece, ou o que toca. A cada dia se passam muitas coisas, porém, ao mesmo tempo, quase nada nos acontece”. Infelizmente, nessa direção, como sinaliza Benjamin (1996), entendemos que a experiência está cada vez mais rara. Vivemos uma pobreza de experiência.

Pela própria dinâmica da pesquisa narrativa percebemos que não há um caminho metodológico único para seguir que funcione para todas as investigações. Como destacam Clandinin e Connelly (2015), as circunstâncias em volta de cada pesquisa, as relações construídas, a vida do pesquisador e as questões investigativas, os diferentes tipos de textos de campo e a versão final dos textos de pesquisa "significam que a pesquisa é frequentemente cheia de incertezas" (Clandinin \& Connelly, 2015, p. 181). Precisamos, no movimento próprio de nossa pesquisa, encontrar o que melhor nos ajudaria a ampliar o olhar acerca do puzzle.

Entendemos, nesse momento, partindo do que destaca Clandinin e Connelly (2015), uma aproximação teóricometodológica, em relação ao uso do termo puzzle e o problema de pesquisa. De acordo com Clandinin (2013), é importante tecer justificativas relacionadas ao puzzle por inúmeras e diferentes razões: i) para compreender nossa posição em relação à pesquisa; ii) sem deixar claro os motivos que nos levaram a pesquisar tal temática, podemos iniciar um processo no qual não estabelecemos nenhuma relação; iii) precisamos compreender quem somos para, a partir daí, compreender as experiências de nossos participantes.

Os argumentos que apresentamos, nos três parágrafos anteriores, para além de definir algumas questões conceituais importantes, nos ajudam a justificar a importância da construção deste artigo. Nessa direção, é importante entender que, como sinalizaram os autores, precisamos compreender quem somos para, a partir daí, compreender as questões envolta as nossas experiências e os motivos que nos levaram a pesquisar tal temática, além de entender esse processo como único para cada pesquisador narrativo. Buscar construir o puzzle de pesquisa pressupõe ligá-lo a nossa história de vida.

Constituí-me, na trajetória de construção da tese, um pesquisador narrativo e, embora a pesquisa que resultou na escrita deste artigo tenha nascido de forma narrativa, reconheço não ser nada fácil, como destacam Clandinin e Connelly (2015), encontrar o movimento entre o que chamam de texto de campo e texto de pesquisa e, também, entre uma escrita formal e uma escrita narrativa. Romper com os modelos de escrita postos pela academia é um desafio que se estende até aqui, quando desta escrita.

Este artigo, principalmente pela natureza do que é proposto, assumirá diferentes "vozes": na primeira pessoa do singular, quando me referir, sobretudo, aos meus posicionamentos, experiências e parte de minha história de vida; na primeira e terceira pessoas do plural quando trouxer discussões que pertencem e foram construídas a partir do contato com os autores que me ajudaram nas discussões.

Nos textos de pesquisa oriundos de pesquisas narrativas, como nos apresentou o Professor Guilherme Prado durante a disciplina "Diálogos entre perspectivas Sócio-Históricas e Narrativas", que participei na Faculdade de Educação da Unicamp

\footnotetext{
${ }^{2}$ Larrosa Bondía, atualmente, tem preferido usar outra palavra em substituição ao termo "experiência". Segundo o autor a palavra foi apropriada pelo mercado. Por isso ele tem falado em "exercício". No entanto, pensando o termo diferentemente do que tem concebido a lógica do mercado, decidimos mantê-lo nesse artigo, seguindo o texto usado para essa fundamentação.
} 
(Universidade Estadual de Campinas), "não há espaço para um leitor preguiçoso, e o texto vai ganhando forma à medida que as experiências acontecem. O vai e vem é normal".

Nesse sentido, em busca de ser mais bem entendido, organizei esse texto da seguinte forma: inicialmente apresentei os primeiros passos e o chegar ao contexto da pesquisa, evidenciando os textos de campo e o percurso para análise dos mesmos; em seguida, tendo em vista o olhar para os meus memoriais de formação, relembro um pouco de minha história de vida e alguns dilemas e desafios de minha formação inicial, continuada e prática profissional, além de refletir sobre algumas questões envoltas ao constituir-se formador de professores. Para finalizar apresento a chegada ao meu puzzle de pesquisa e construo algumas considerações ao trabalho. Nessa leitura, caros leitores, considerem o "vai e vem" e os diferentes tempos verbais como necessários para composição desse texto de pesquisa.

\section{Dos Primeiros Passos ao Contexto da Pesquisa}

Este artigo foi construído a partir da revisita aos memoriais que construí ao longo de minha vida acadêmica e profissional, principalmente ao do presente em minha dissertação e tese; bem como de outros artigos publicados, a exemplo de: Silva e Passos (2020), Silva (2020a), Silva (2020b), Silva (2020c), Silva e Passos (2019) e Silva e Passos (2016). Revisitando as experiências narradas, e (re)pensando sobre elas, alguns fragmentos se mantiveram, ganhando como ponto de reflexão as perspectivas que permearam a construção da tese. Nessa direção, portanto, Josso (2007, p. 413) destaca que "as narrações centradas na formação ao longo da vida revelam formas e sentidos múltiplos de existencialidade singular-plural, criativa e inventiva do pensar, do agir e do viver junto".

Tendo em vista a importância da reflexão para o processo formativo e constituição da identidade docente, este texto objetiva apresentar, como destaca Guedes-Pinto (2012), as memórias construídas pelo conjunto de relações. Para tanto, tomo como referência a minha formação acadêmico-profissional, reconhecendo, nesse recorrer às memórias - corroborando o que destaca Souza (2006) - uma dupla funcionalidade: pesquisa e formação.

Nessa direção, Clandinin e Connelly (2015) alertam que a pesquisa narrativa começa com a narrativa do pesquisador orientada autobiograficamente, constituindo o puzzle de pesquisa. É esse o exercício que farei aqui. De qualquer forma nos cabe destacar que a pesquisa realizada foi qualitativa e baseada, como percebido até aqui, nos princípios da narratividade, como bem apresentam Clandinin \& Connelly (2015).

De acordo com Kenski (1996), referenciado por Guedes-Pinto (2012), o exercício de rememoração feito com professores pode trazer pistas e colocar em evidência sua prática docente. Visitar o passado nos faz considerar o presente, já que são as situações vividas [no presente] que motivam essa visitação. Esse processo de rememoração, segundo a mesma autora, está intimamente ligado à construção da identidade do narrador, pois, ao reconstruir nossa memória, estamos no processo simultâneo de tentativa de modificar o presente e alterar o futuro.

Nesse sentido, é importante considerar que as narrativas, como a construção de memórias a partir das experiências do narrador, constituem-se como importante ferramenta de formação por permitir, consoante Guedes-Pinto (2012), uma ruptura instauradora, reconsiderando a ideia de verdade como fixa, estável e inquestionável.

Para a escrita deste artigo, decidi revisitar as construções narrativas produzidas ao longo de meu processo de formação, desde a graduação até o doutorado. Os memoriais construídos durante a graduação, o do concurso para ingresso no ensino superior como docente, o do mestrado e o do doutorado serão textos de campo que permitirão perceber aproximação de minha história de vida ao puzzle de pesquisa no doutoramento ${ }^{3}$.

O recorte mnemônico é o que considera as memórias de minha vida acadêmica e profissional. Porém, haja vista o fato

\footnotetext{
${ }^{3}$ Foi nosso puzzle no doutoramento: o que revelam narrativas de licenciandos do curso de Pedagogia da UFSCar, construídas ao longo da formação, sobre a ludicidade, o ensino de matemática e o constituir-se professor que ensina matemática nos anos iniciais?
} 
de considerar que as vivências ocorridas antes do início do desenvolvimento profissional ${ }^{4}$ trazem implicações para a constituição da identidade docente, em alguns momentos, ampliarei esse recorte para apresentar fatos que julgo pertinentes. Considerando essa trajetória, darei ênfase, sobretudo, ao processo de formação e atuação profissional, destacando pontos desses momentos que figuram como importantes reflexões formativas, e que se ligam às discussões de formação do professor que ensina matemática e ludicidade, objetos de nosso puzzle de pesquisa.

Textos de campo, como nos apresentam Clandinin e Connelly (2015), são aqueles que são criados, não são encontrados e nem descobertos pelos participantes e pesquisadores. Eles objetivam representar aspectos da experiência de campo. "Os textos de campo auxiliam o pesquisador a mover-se retrospectivamente e prospectivamente em um completo envolvimento com os participantes e também distanciamento deles" (Clandinin \& Connelly, 2015, p. 119).

Ainda segundo os autores anteriormente referenciados, a relação do pesquisador com a história em andamento do participante, [nesse caso sou o pesquisador e participante simultaneamente], configura a natureza dos textos de campo e estabelece seu status epistemológico (Clandinin \& Connelly, 2015, p. 136). Assumimos, nesse sentido, que um relacionamento embute sentido nos textos de campo e impõe a forma com que o texto final de pesquisa será desenvolvido.

Embora o movimento de transição para transformar textos de campo em textos de pesquisa seja uma tarefa difícil e complexa, como nos apresenta Clandinin e Connelly (2015), o texto de pesquisa é quando usamos o que foi construído no texto de campo na escrita do artigo, por exemplo.

Narrar a própria história, como destaca a Caporale (2016, p. 54), fundamentando-se em Finger e Nóvoa (2010), "desencadeia processos de reflexão e (re)significação dos sujeitos, compondo, portanto, de espaços de investigação e de formação". Partindo do que nos apresenta, compreendemos que é essa mesma reflexão que nos guia no processo de análise e interpretação dos textos de campo e escrita do texto de pesquisa, pois se trata de "um processo coletivo de mútua explicação em que a vivência do investigador se imbrica na do investigado" (Cunha, 2007), sem perder de vista os conceitos que lhes são inerentes: a experiência, a temporalidade, a reflexividade, as interações e os contextos em que as histórias estão inseridas.

Nesse caso, ainda levando em consideração ao que nos apresenta Caporale (2016), as histórias de vida, como apresentadas neste artigo, não se referem a algo externo a ser incluído na pesquisa, pois elas são a própria pesquisa. A análise dos textos de campo, portanto, não se limitam a dizer como as experiências ocorreram, ela vai muito além, principalmente quando pensamos e expressamos como pesquisador e participantes "vivem, contam e interpretam suas histórias e criam novas histórias a serem vividas" Mello (2004, p. 91) apud Caporale (2016, p. 80).

Ainda segundo Caporale (2016) é mais produtivo compor significados a partir do que os dados nos permitem entender do que encontrar ou ver significados nos dados. Dessa forma, portanto, "a interpretação dos dados, pode ser realizada por meio da composição de sentidos, que envolve as diversas leituras dos dados; a escrita e reescrita do texto; o pensar e repensar sobre os dados; a apresentação do que foi escrito em um grupo, para que possa receber sugestões/críticas; entre outras possibilidades" (Caporale, 2016, p. 80). Durante esse processo de composição de significados é preciso fazer escolhas e refletir profunda e continuamente sobre as histórias de vida dos participantes. Trata-se de um trabalho artesanal e único.

Nessa direção, no intuito de compor o texto de pesquisa, foi preciso interagir com os textos de campo compostos pelos quatro memoriais (do fim da graduação, da seleção para ingresso como docente em Universidade, do mestrado e do doutorado). Procuramos como fez Caporale (2016, p. 80), "ter um olhar em todas as direções, retrospectiva e prospectivamente, procurando perceber cada sujeito, seus sentimentos, suas indignações e indícios de sua construção identitária, entre outras possibilidades".

\footnotetext{
4 “Será que esse desenvolvimento tem começo? No caso do professor, qual seria?". Penso que é no momento que se toma a docência como atividade profissional que esse desenvolvimento se inicia. Antes disso, sem um pensar sistematizado sobre o que está envolto a sua formação e prática profissional, não se consegue pensar na historia de vida, por exemplo, e entender suas implicações para a construção da identidade docente;
} 
Procuramos, ainda referenciando o percurso construído por Caporale (2016, p. 81), "conhecer e compreender introspectiva e extrospectivamente os contextos de vida e de formação nos quais ocorreram as experiências de vida e situá-los num lugar". Não perdendo de vista o captar as múltiplas vozes, as explícitas e as implícitas, contidas nas histórias contadas por mim, pesquisador e participante desta pesquisa; e recontar essas histórias a partir de intensas reflexões e interpretações das experiências.

\section{Relembrando um Pouco de Minha História de Vida}

Sou o primogênito de um total de três filhos de uma família de trabalhadores que nascidos e crescidos no interior do estado da Bahia, aprendeu a conviver no semiárido, e descobriu, na Educação, um potencial de mudanças significativas.

Do lado materno, as referências são de uma jovem nascida em uma fazenda, de onde os seus pais resolveram migrar para o centro urbano para permitir que os seus dezessete filhos tivessem acesso à educação, e que ela, mais tarde, se tornasse professora. Do lado paterno, o filho de uma lavradora e de um operador de máquinas, que teve que enfrentar a dura realidade de morar em cidade distante dos familiares para poder concluir os seus estudos e, posteriormente, tornar-se um bancário.

Ter nascido dessa união representa um processo único de significação, pois obtive referência para a construção de minha história e de minha essência como cidadão e como profissional. Por essa razão, traço, neste item, um relato sobre a minha trajetória, tendo o histórico familiar como parte indispensável no processo educativo.

Lembro-me, só que muito pouco, mas com carinho, dos momentos em que minha mãe, na época cursando o magistério, me levava para sala de aula. Era uma criança, claro, mas já estava sendo introduzido nos espaços de formação de professores. Seria esse, então, o primeiro momento de aproximação com esse campo? Seria por isso minha familiaridade e prazer em atuar, hoje, enquanto professor/formador de professores? Sei que foram momentos que me marcaram, afinal, lembro-me "com carinho", como destaquei. Mas era uma criança e, embora marcantes, essas questões, naquela época, obviamente, passavam despercebidas, ou melhor, não eram objeto de reflexão.

Em minha infância, recordo-me também, dos inúmeros momentos de lazer, das diversas vezes que, simbolicamente, dei vida a objetos que me serviam de brinquedo. Seres inanimados tornavam-se o que eu queria que se tornassem, sem nada muito sofisticado, muita tecnologia ou equipamentos de última geração. Divertíamo-nos com muito pouco e aprendíamos, desde cedo, a partir de um processo de criação, a revestir coisas com significado ${ }^{5}$, algo extremamente importante no processo de ensino e aprendizagem, como descobri depois. Daí questiono: os conhecimentos necessários para a atividade docente se desenvolvem apenas durante uma formação inicial ou continuada $?^{6}$ Em que medida os elementos de vida do sujeito e seu contato, durante toda a vida, escolar ou não, são importantes para esse processo de constituição do sujeito enquanto professor?

Destarte, levando em consideração o que é apontado por André (2010, p. 175), fundamentando-se em Marcelo Garcia (2009), cabe destacar que, nesses processos de desenvolvimento profissional, é importante dar atenção às representações, crenças, preconceitos dos docentes, pois elas vão afetar sua aprendizagem da docência e possibilitar ou dificultar as mudanças. É igualmente necessário fazer vir à tona essas representações ${ }^{7}$ e analisá-las criticamente, junto com os professores, para poder

\footnotetext{
${ }^{5}$ É mais ou menos o que acontece no processo de transformação de um material em didático. Ao revestir um material qualquer com significado de contribuição para a aprendizagem, estamos construindo um material didático. Isso fica muito claro no processo de construção e exploração do brinquedo Spoc por Passos (2010);

${ }^{6}$ Lortie (1975) apud (FLORES, 2010), nesse texto, revela que a "aprendizagem pela observação", associada às predisposições pessoais, às imagens sobre o ensino, sobre a aprendizagem e sobre o que significa ser professor, constitui um elemento central para a compreensão do processo de aprender a ensinar. O autor chama a atenção para a influência determinante da "aprendizagem pela observação", em resultado da experiência escolar ao longo de milhares de horas que os alunos (futuros professores) passaram no contexto da sala de aula. Ainda de acordo com o autor esta cultura latente é (re)ativada durante a formação inicial persistindo ainda no momento da prática profissional.

7 "nem sempre tais representações são identificáveis". Nossa escrita refere-se, sobretudo, as que são manifestas e apresentadas pelas estudantes, futuras professoras. Entendemos "que esse também não seja um processo individual, mas coletivo e representações são sociais e não necessariamente individuais". Essa construção, de forma geral, respalda-se nesses princípios;
} 
encontrar formas de transformá-las. Além disso, como nos apresenta Oliveira (2011), uma referência importante para o desenvolvimento da ação docente, nesse processo de formação de professores, é o modo como os futuros professores se relacionam com o conhecimento em sua experiência escolar.

Ainda segundo Oliveira (2011), muitas dessas crenças construídas e com as quais os estudantes chegam ao curso de formação inicial, são resultados do longo período em que esses futuros professores estiveram na condição de aluno, observando as inúmeras práticas formativas apresentadas ao longo de sua vida escolar. Dessas, portanto, como nos apresenta a autora, referenciando Marcelo e Vailant (2009), a identidade docente vai se configurando de forma paulatina e pouco reflexiva.

Nesse sentido, cabe-nos considerar esses elementos subjetivos, muitos deles oriundos de vivências anteriores ao processo de formação inicial, como importantes e possíveis de uma sistemática análise e tratamento, já que, recorrendo ao que apontou André (2010), cabe, nesses casos, uma análise crítica em busca de maneiras de transformá-las na direção desejada; ou seja, é preciso levar em consideração que esse não tratamento [às crenças, representações e preconceitos] pode trazer implicações negativas ao processo de formação, pois, ainda segundo os autores anteriormente referenciados, a identidade profissional é um elemento inseparável do desenvolvimento profissional.

Refletindo sobre o que destaquei anteriormente, alguns outros questionamentos surgem e fazem-me pensar sobre algumas problemáticas que identifico ao longo de minha trajetória de vida e profissional e que podem, de algum modo, implicar na forma como se percebe a ludicidade e o uso de ferramentas com potencial lúdico em uma futura prática. As famílias asseguram a garantia desse direito? É preciso, como preconiza o Estatuto da Criança e do Adolescente (ECA), garantir à criança o direito ao lazer. Nesse sentido, se reconhece que brincar é uma necessidade, e a família, nesse contexto, também é importante para assegurar esse direito.

Como as crianças brincam? Qual a relação que se estabelece com o objeto lúdico tendo em vista que, muitas vezes, se apresenta esse mesmo objeto como algo ruim e como perda de tempo? Quando professor, se vivenciadas situações negativas a respeito do brincar, será que essa mesma prática seria assegurada aos alunos? O que é preciso para (re)significar tudo isso?

Alves (2012), ao discutir aspectos da ludicidade no ensino da matemática, apresenta que o modo como via os jogos e as brincadeiras, imagem construída ainda na infância, foi importante no processo de utilização dessas ferramentas em suas aulas. Nesse caso, pontuo a necessidade de, no processo de formação do futuro professor, promover momentos de rememoração dos jogos e brincadeiras da infância, trazendo para o presente a vivência dessas experiências, com o objetivo de (re)significar a imagem construída ao longo de sua trajetória.

Durante meu percurso de estudante da Educação Básica, além dos responsáveis pela Educação Física, não me recordo de professores que tiveram uma prática lúdica. A matemática nos era apresentada como uma disciplina desarticulada do cotidiano, uma ciência cristalizada e imutável. As ressignificações, quando aconteciam, eram feitas por cada estudante, de sua maneira, através de suas vivências; além disso, as diferentes matemáticas produzidas no contexto sociocultural do sujeito, como refletem D'Ambrosio (1998) e Knijnik (1997), não eram valorizadas e nem se constituíam como ponto de partida no processo de ensino e aprendizagem. Dói-me ver que, infelizmente, as coisas mudaram muito pouco, ou quase nada.

Ao fim do Ensino Médio, veio a difícil tarefa de decidir o destino de minha vida profissional. Mesmo a docência não sendo uma atividade muito atrativa, como pontua Linhares (2008), por não ter muitas opções de cursos, escolhi a Licenciatura em Matemática. Sabia dos impactos profissionais de minha escolha, pois, naquele momento, usava como referência apenas a necessidade de profissionais na área de exatas. 


\section{Alguns Dilemas e Desafios de Minha Formação Inicial, Continuada e Prática Profissional}

A formação docente tem que ser pensada como um aprendizado profissional ao longo da vida, o que implica envolvimento dos professores em processos intencionais e planejados, que possibilitem mudanças em direção a uma prática efetiva em sala de aula (André, 2010, p. 176).

Optei, para dar início a essa seção, em trazer esse excerto do texto de Marli André, sobretudo por considerar oportuna a discussão feita. Primeiro, corroboro o que é destacado pela autora sobre pensar a formação docente como resultado de aprendizagens que acontecem ao longo da vida, e acrescento que acredito que a formação é marcada tanto pelo que aconteceu antes do seu início, bem como é vulnerável aos percalços do processo. Nesse sentido, é importante que os professores envolvidos nessa formação, intencionalmente e de forma planejada, possibilitem mudanças. Porém, não foi essa a impressão que tive durante a realização do curso de licenciatura. Pelo contrário. Infelizmente percebia a pouca [ou nenhuma] ligação dos meus professores com essas questões. Muitos estavam em um curso de formação de professores de matemática, mas desconheciam o que deveria saber esse profissional, ou melhor [ou pior], achavam que sabiam a única coisa necessária: dominar, apenas, o conteúdo.

Percebendo essa problemática como histórica, cabe destacar, como aponta Gatti (2010, p. 1357), que, "mesmo com ajustes parciais em razão das novas diretrizes, verifica-se nas licenciaturas dos professores especialistas a prevalência da histórica ideia de oferecimento de formação com foco na área disciplinar específica", havendo pequeno espaço para a formação pedagógica. Adentramos, ainda segundo a autora, no século XXI, em uma condição de formação de professores nas áreas disciplinares em que, mesmo com as orientações mais integradoras quanto à relação "formação disciplinar/formação para a docência", na prática, ainda se verifica a prevalência do modelo consagrado no início do século XX para essas licenciaturas.

Assim que iniciei o curso, no Centro de Ensino Superior do Vale do São Francisco (CESVASF), localizado no município de Belém do São Francisco-PE, comecei a me identificar com a área de Educação Matemática e a visualizar sua ligação e importância com o processo de formação do professor. Costumo destacar que o lúdico foi o elemento de conquista, pois foi ele que me despertou o interesse pela docência e, principalmente, com ele, passei a buscar formas de dinamização do ensino e de desconstrução da imagem, aquela cristalizada, imutável e difícil apresentada anteriormente, que a matemática possui.

Durante o primeiro semestre do curso, a professora de Prática Pedagógica I dividiu a turma em grupos as temáticas de discussão dos Parâmetros Curriculares Nacionais (PCN), e eu fiquei responsável por falar sobre os jogos e o ensino da matemática. Foi a partir daí, e de minha primeira experiência como docente, acontecida logo depois, que me envolvi com a docência, já que não queria, inicialmente, fazer uma licenciatura e nem me tornar professor.

É engraçado que, além dos relatos de minhas experiências enquanto professor, já presentes desde o primeiro semestre do curso, outros figuram no memorial feito no último semestre da graduação. Uma dessas experiências foi, justamente, da apresentação do seminário com a temática de jogos. Pensando sobre a experiência vivida eu escrevi: "sabe quando, na verdade, parece que você foi escolhido? Pois é, a sensação que tive é que os jogos me escolheram para estudá-los. Parece que viram em mim algo que, naquele momento, confuso pelas questões de escolhas profissionais e imaturo pela pouca idade, nem eu mesmo via”. É interessante revisitar essa escrita e perceber que desde aquela época - e olha que já se passaram alguns anos -, esse episódio me marcou e me fez olhar para a área de educação matemática, e principalmente para as questões de ludicidade, com outros olhos, diferente do de muitos outros colegas do curso.

Lembro-me muito bem dessa minha professora. Professora sensata, conhecedora da realidade educacional brasileira e articuladora de questionamentos e atividades que, ao longo das disciplinas, nos faziam refletir sobre uma futura prática [ou prática, para os inúmeros colegas que estavam no processo de formação inicial, mas já eram professores há alguns anos]. Lembro-me de Walter, um de meus colegas, que era professor de matemática há mais de vinte anos, e que, durante as aulas de 
Prática Pedagógica, trazia algumas contribuições interessantes que nos faziam pensar sobre inúmeras situações vividas por ele no contexto escolar. Como era legal ouvi-lo falar sobre as diversas vezes que enfrentava os problemas que surgiam em sala de aula e debater com a professora, que o colocava, às vezes, principalmente quando percebia uma postura não aberta ao diálogo, para refletir um pouco mais.

Um ponto que merece destaque é a ausência de espaços de pesquisa durante a minha formação. Vale destacar que esses espaços, quando propiciados, surgem como "eixo estruturante da formação inicial que pode ultrapassar a visão dicotômica e redutora da 'prática' identificada com o que acontece na escola e a 'teoria' com o que acontece na universidade" (Flores, 2014, p. 225).

Esteves (2006, apud Flores, 2014, p. 225) afirma que um modelo de formação que seja orientado para a investigação, “é essencial para o desenvolvimento do ensino e do conhecimento sobre o ensino através da pesquisa, incluindo a análise dos contextos de trabalho dos professores". Desse modo os alunos, futuros professores, se assumem como alunos e também como investigadores (Loughran, 2009), implicando no desenvolvimento de competências investigativas e de uma postura crítica diante do ensino e dos contextos da sua realização.

Infelizmente, não me recordo de muitos momentos durante o curso, espaço de profissionalização ${ }^{8}$, em que me envolvi com outro tipo de atividade que não o ensino. Sabemos da tríade que fundamenta o Ensino Superior (Ensino, Pesquisa e Extensão), e da importância de, ao futuro professor, se assegurar essas diversas práticas. Não sei se a ausência dessas vivências se deve ao fato de ter participado de um curso noturno e essas atividades serem pouco ofertadas ao público (acredito que não), ou de fazer uma licenciatura e estar trabalhando, situação que me faz assumir a falta de tempo e a impossibilidade de participar das atividades propostas (se propostas). Acredito que possuía uma série de questionamentos, oriundos de minha prática em sala de aula que poderiam ser melhor respondidos através de atividades de pesquisa, por exemplo. Porém, precisei, a partir dos erros e acertos da prática, buscar essas respostas; muitas delas, sozinho.

Foi nesse cenário de escolhas e descobertas que comecei a desvendar as várias faces do agir pedagógico, percebendo que o ato de ensinar não será verdadeiramente de qualidade se não houver uma boa relação entre os conhecimentos do conteúdo - muito evidenciados durante o curso de Licenciatura em Matemática -, os conhecimentos pedagógicos, tão importantes para a profissionalidade ${ }^{9}$ e construção da identidade docente, e as questões lúdicas, pois é bem melhor quando fazemos algo e nos divertimos fazendo.

Durante todo o tempo de graduação, o contato com ótimos professores de Prática Pedagógica, Didática e de Estágio Supervisionado, profissionais que conheciam o "chão da sala de aula" e oportunizaram a compreensão da difícil realidade das escolas públicas no Brasil, do ensino da matemática, auxiliou no processo de construção e (re)significação da ação pedagógica, ensinando-nos a respeitar as especificidades dos educandos.

No início da graduação, no primeiro semestre, comecei a trabalhar em uma escola pública estadual, o que também contribuiu para a formulação de alguns questionamentos que me inquietavam e me faziam refletir sobre a minha prática docente. Confidencio que, por meio de minhas observações e vivências na graduação, muitos professores julgavam o conhecimento pedagógico dispensável da formação inicial do professor de matemática, apresentando o fraco argumento de que é por meio, apenas, da experiência profissional que se constrói a relação entre teoria e prática e que a vivência profissional responsabilizar-se-ia por essa questão na formação.

Indo ao encontro do que é apresentado, Gatti (2010), em âmbito nacional, destaca como alguns cursos têm pensado

\footnotetext{
8 "Profissionalização de professores implica a obtenção de um espaço autônomo, próprio à sua profissionalidade, com valor claramente reconhecido pela sociedade". Gatti (2010, p. 1360);

9 Entendemos, segundo o destaque de Gatti (2010, p. 1360), fundamentando-se em Ramalho, Nuñez \& Gauthier (2003), "que a profissionalidade é o conjunto de características de uma profissão que enfeixam a racionalização dos conhecimentos e habilidades necessárias ao exercício profissional”.
} 
[ou não] essa articulação entre teoria e prática, principalmente nas propostas curriculares que possuem. Segundo a autora, há um "grande desequilíbrio entre teorias e práticas, em favor, apenas das teorizações mais abstratas" (Gatti, 2010, p. 1370), ou seja, preocupam-se mais com o oferecimento de teorias políticas, sociológicas, psicológicas, por exemplo, que são importantes para o trabalho consciente do professor, mas que não são suficientes para o desenvolvimento de sua prática pedagógica, o que fragiliza, de certa forma, essa formação para o exercício do magistério na educação básica. Essa problemática também é experimentada em outros países, como destaca Flores (2014).

Preocupar-se com os currículos dos cursos de formação inicial é algo legítimo e importante, porque, de acordo com Zeichner \& Gore (1990, apud Flores, 2014, p. 219), "a influência socializadora da formação inicial depende da natureza, do modelo e da estrutura do curso de formação, mas também das crenças e das perspectivas pessoais que os alunos trazem consigo". Outra questão posta pelos autores é a concepção dos professores subjacentes aos cursos de formação, quer no currículo real ${ }^{10}$, quer no currículo oculto ${ }^{11}$.

Não me recordo de professores que tenham, durante a graduação, demandado algum tempo para pensar suas propostas de trabalho a partir das inúmeras realidades, perspectivas pessoais e o que levávamos conosco. Boa parte dos professores que apresentava essa prática era das disciplinas pedagógicas ou da área de educação matemática. Os professores das disciplinas do campo específico da matemática, às vezes sem nem saber os reais motivos dessas práticas voltadas para a formação docente, discordavam das posturas adotadas por aqueles professores.

Sempre discordei desse discurso de que o conhecimento pedagógico é desnecessário para a profissionalidade do professor de matemática. Por outro lado, desde o princípio, também percebi que o ensino dessa ciência precisava de uma base teórica sustentável, a partir de uma prática pedagógica fundamentada dentro da realidade sociocultural do sujeito, de modo a tornar o processo de ensino e aprendizagem, além de mais prazeroso, efetivamente mais produtivo. Nessa busca, tive contato com o lúdico e passei a percebê-lo como dimensão ampla de formação, também muito pouco trabalhada e discutida, mas que poderia desconstruir a imagem negativa que muitos possuem da matemática ${ }^{12}$.

Não me sentia preparado para assumir uma sala de aula, já que estava no início do curso e não tinha tido contato com boa parte das disciplinas e achava não possuir profissionalidade para tal. Mesmo assim, tendo em vista a tão sonhada independência financeira, decidi assumir. Eram turmas do Ensino Médio e eu possuía apenas 17 anos. Na escola, me senti sozinho. Mesmo sendo visivelmente mais jovem e inexperiente, os professores e equipe gestora que já trabalhavam há mais tempo não se preocupavam em orientar ou acompanhar minimamente o meu trabalho.

Como destaca Gatti (2010), em função dos graves problemas que enfrentamos no que diz respeito às aprendizagens escolares em nossa sociedade, a qual se complexifica a cada dia, cresce a preocupação com as licenciaturas, "seja quanto às estruturas institucionais que as abrigam, seja quanto aos seus currículos e conteúdos formativos” (Gatti, 2010, p. 1359).

Por que as universidades não acompanham os seus estudantes que iniciam a atividade docente antes do término da graduação, já que isso é tão comum de acontecer? Penso que, se eu tivesse tido uma experiência negativa, e não tivesse conseguido resolvê-la internamente, não teria assumido a docência como minha atividade profissional ou talvez não tivesse concluído o curso de licenciatura. Nesse caso, claro que passei por inúmeras situações conflitantes, mas usei-me da resiliência

10 "É o currículo que de fato acontece na sala de aula em decorrência de um projeto pedagógico e um plano de ensino. É a execução de um plano, é a efetivação do que foi planejado, mesmo que neste caminho de planejar e do executar aconteça mudanças, intervenção da própria experiência dos professores, decorrente de seus valores, crenças e significados" (Libâneo, 2007, p.172);

11 "O currículo oculto é representado pelas influências que afetam a aprendizagem dos alunos e o trabalho do professor provenientes da experiência cultural, dos valores e significados trazidos pelas pessoas de seu meio social e vivenciado na própria escola, ou seja, das práticas e experiências compartilhadas em escola e na sala de aula" (Libâneo, 2007, p. 172).

12 "Qual o papel do lúdico para uma mudança ou desconstrução de uma imagem negativa da matemática?". A ludicidade, pensando na direção do questionamento feito, e o percebendo como um aspecto da formação humana, também, aproxima os estudantes da matemática na medida em que permite que os mesmos, por meio das diferentes estratégias formativas que caracterizam o objeto lúdico, a perceba de tal forma. Consideramos, via sua fala, que existe o desprazer no ato de jogar, isso é discutido na psicanálise, mas levando em consideração a liberdade como característica, entendemos que os momentos de prazer e a relação que isso estabelece com a aprendizagem são marcantes. 
para sobrepor os obstáculos. Nesse sentido, indo ao encontro do que sinaliza Day (2014), considero a resiliência uma característica profissional importante para o docente, sobretudo no quadro problemático em que se encontra a educação brasileira, como destacamos no texto introdutório.

Nesse sentido, sobretudo motivado pelas questões que são apresentadas por Flores (2014), defendo a necessidade de se perceber a escola como um local de aprendizagens profissionais e de formação. Caminhando nessa direção, apresento as ideias postas por Cerrilo (2001), destacando que o comportamento do professor será moldado pelo seu espaço de trabalho, uma vez que se estimula a criatividade e se permite a autorreflexão sobre a ação. Infelizmente, muitos gestores não reconhecem esse papel e não criam espaços de reflexão e formação.

Conforme Estola, Minna e Syrjala (2014), apud Flores (2014, p. 11), "tornar-se professor é um processo multifacetado que continua para além da formação inicial incluindo não só as questões identitárias, mas também as dimensões emocionais, morais e políticas", defendendo que a reflexão e a narratividade constituem elementos importantes para a sua análise e desenvolvimento pelos candidatos a professor e professores em exercício.

É claro que não quero culpabilizar o professor e sua formação pelos problemas enfrentados pelas redes de ensino; pelo contrário, como aponta Gatti (2010, p. 1359) "múltiplos fatores convergem para isso: as políticas educacionais postas em ação, o financiamento da educação básica, aspectos da cultura nacional, regionais e locais, hábitos estruturados". A autora ainda apresenta como fatores a naturalização da situação crítica das aprendizagens efetivas de amplas camadas populares, as formas de estrutura e gestão das escolas, a formação dos gestores, as questões sociais e escolarização de pais e mães de alunos menos favorecidos (os "sem voz"13) e a formação inicial e continuada, os planos de carreira e salário e as condições de trabalho nas escolas.

Sendo assim, diante do quadro em que se encontra a educação no Brasil, cabe- nos questionar: qual o papel da escola e dos professores? Gatti (2010, p. 1360), apresenta como resposta ao questionamento feito que à escola e ao professor cabem a tarefa de ensinar-educando, "uma vez que postulamos que sem conhecimentos básicos para interpretação do mundo não há verdadeira condição de formação de valores e de exercício de cidadania".

Foi nesse momento de busca constante, de dúvidas frequentes e de questionamentos intermináveis que, ainda no fim da graduação, decidi fazer a especialização em educação matemática, na esperança de que muitas das dúvidas deixadas durante a formação inicial fossem sanadas. Objetivei obter respostas para uma série de questões, mas cedo percebi que, quanto mais procuro respostas, mais perguntas aparecem. Ora, é exatamente essa gama de questionamentos e a busca de suas respostas que constituem o perfil de um professor pesquisador, perfil este com o qual me identifico, pois diz respeito à minha prática em sala de aula, cuja finalidade é aprimorar a construção de um melhor processo formativo.

Acredito em uma educação matemática que oportunize o contato com o conhecimento matemático, e que através desse contato seja possível fazer ligações com as questões do cotidiano. Ou melhor seria, como aponta D’Ambrosio (1998), que a formação em educação matemática levasse em conta o cotidiano, as vivências do sujeito e as matemáticas produzidas como ponto de partida para a construção desses conhecimentos. Nesse sentido, os jogos e as brincadeiras, importantes ferramentas de caracterização do lúdico, permitem a vivência de uma série de situações problematizadoras que facilitam o processo de ensino e aprendizagem e, consequentemente, a construção de conceitos, justamente porque contribuem para a percepção de que a matemática já faz parte das atividades cotidianas das pessoas. Assim, também, conseguimos encontrar um caminho metodológico que desmistifica a matemática como "bicho de sete cabeças", criada pela nossa cultura escolar.

\footnotetext{
${ }^{13}$ Entendemos que eles têm vozes, mas não são ouvidos. Então, talvez fosse mais razoável a expressão: “cujas vozes não são ouvidas". No entanto mantivemos essa por ter sido a que foi usada pela autora;
} 


\section{De Professor a Formador de Professores}

Queremos conhecer mais e melhor os professores e seu trabalho docente porque temos a intenção de descobrir os caminhos mais efetivos para alcançar um ensino de qualidade, que se reverta numa aprendizagem significativa para os alunos. Isso supõe, por um lado, um trabalho colaborativo entre pesquisadores da universidade e os professores das escolas, e por outro lado um esforço analítico muito grande, seja no interior dos grupos de pesquisa, seja entre grupos para reunir elementos que ajudem a reestruturar as práticas de formação. (André, 2010, p. 176)

Cheguei à Universidade do Estado da Bahia - Uneb, Campus IX, como professor do curso de Licenciatura em Matemática, em 2010, e as minhas inquietudes se mantinham: por que, mesmo sabendo da importância e contribuição do lúdico, há resistência por parte de muitos professores em sua utilização? Movido por essa questão, assumi em 2012 a coordenação do Laboratório de Educação Matemática. Nesse espaço ofereci algumas atividades de extensão, para estudantes dos cursos de Matemática e Pedagogia e professores da rede pública, e pensei em outras atividades de pesquisa, no intuito de contribuir para a formação do professor e para, coletivamente, buscarmos possíveis respostas.

Foi nessas condições que o meu problema de pesquisa do mestrado nasceu. Na tentativa de responder, percebi que há a necessidade de uma formação lúdica para o professor, essa formação que me foi negada durante a formação inicial, assim como foi negada a outra gama de professores. Porém, será que, diferentemente da minha formação, o curso no qual atuo possibilita isso? Como posso abordar a dimensão lúdica no processo de formação inicial do professor que ensina matemática? Na busca, também, dessa resposta nasceu o meu problema de pesquisa para seleção do doutorado. Acreditam? É aquela mesma sensação de que quanto mais procuro respostas para minhas perguntas, mais perguntas aparecem. Durante o percurso do doutoramento muita coisa, ou quase tudo, mudou.

Nesse processo de constituir-me formador de professores, cabe uma digressão para relatar um episódio que considero importante: o contato enquanto gestor escolar. Recebi o convite de assumir a gestão de uma escola quando estava ainda no $3^{\circ}$ semestre do curso de Matemática e assustei-me, sobremaneira, com os desafios que essa atividade apresentava para mim, mas resolvi aceitar.

As pessoas mais próximas, sempre apontavam como características minhas um perfil de liderança e consideravam-me criativo e com capacidade de envolver os sujeitos. Se tratando de gerir uma escola, acreditavam que eu faria isso pensando na qualidade do ensino e da aprendizagem dos alunos. E foi isso justamente o que fiz. As vivências com o cargo de gestor me permitiram perceber a educação e o processo de desenvolvimento profissional docente de outra forma, fazendo-me envolver com questões que permeiam vários aspectos do processo educativo. Porém, confesso: não achava que um perfil criativo e liderança eram suficientes. Na época não, mas, hoje, vejo o quanto estava despreparado para assumir aquela função. Mesmo tendo aprendido muito com ela, lógico, eu sabia muito pouco sobre ser gestor, faltava-me, sobretudo, o conhecimento teórico, formação, e a vivência de experiências.

Interessante que sempre pensei o espaço escolar da forma como destaca Roldão (2007), fundamentada em Canário (1991): o contexto de trabalho, como poderoso agente da apropriação do saber e da prática profissional e da construção da cultura escolar e docente, integrando o processo formativo. Nesse sentido, criava, nos momentos de planejamento coletivo, propostas para estudos e discussões que contribuíssem para a formação e prática desses professores, muitos que, assim como eu, estudavam e trabalhavam concomitantemente.

Mesmo em início de carreira, diferente dos demais colegas, entendia que poderia aprender com as experiências deles; por isso, a importância da criação de um espaço em que refletíssemos juntos sobre as questões que nos inquietavam. Era gestor e, como tal, assumia essa responsabilidade por ver a direção escolar, como pontua Cerrilo (2001), como arte, ciência aplicada e espaço de uma prática reflexiva.

Hoje, percebo que meu envolvimento com a formação de professores se deu desde essa experiência profissional como 
gestor escolar. Foi ela que me levou a buscar formação continuada em gestão escolar e em psicopedagogia, por exemplo. Queria estar preparado para os desafios que me fossem (im)postos.

Tornou-se um sonho, depois de envolvido com o processo de formação de professores, ir para a universidade e trabalhar diretamente com os cursos de licenciatura. Queria contribuir mais, de alguma forma, com esse processo. Pensava, diariamente, em muitas atividades de pesquisa e extensão que poderiam ser desenvolvidas. Engraçado que sempre usava como base de reflexão a minha formação; então, pensava em atividades que me foram negadas, por exemplo, e que queria ter tido. Mais tarde, percebi também que, mesmo afastados geograficamente por 934 quilômetros de distância, já que tinha feito o meu curso no estado de Pernambuco e o curso que trabalhava era no estado da Bahia, as oportunidades formativas oferecidas pelas licenciaturas eram parecidas.

Antes de chegar à Universidade do Estado da Bahia, como professor, trabalhei em alguns cursos de graduação e especialização em instituições privadas, além de ser convidado, todos os anos, para fazer parte da equipe de uma empresa que realizava jornadas pedagógicas pelos municípios baianos. Confidencio que foram experiências ímpares, uma vez que viajávamos por várias cidades do estado da Bahia e conhecíamos diferentes culturas e realidades escolares.

Em 2009, surgiu o edital do concurso para a área de Estágio nos cursos de Licenciatura em Matemática. Tinha apenas 22 anos, e sentia-me, mais uma vez, semelhante a quando assumi a direção da escola, despreparado para essa atividade. Tinha uma certeza: É isso que quero fazer pelo resto da vida. Como é engraçada a vida, não é? Eu que, me repetindo, nunca pensei em fazer um curso de licenciatura, tampouco em ser professor. Sonhava em fazer Psicologia e atuar na área. Porém, dentro do curso, eu me encontrei profissionalmente a ponto de, nesse momento, não pensar em fazer outra coisa. Se pudesse voltar no tempo e escolher o curso novamente, escolheria fazer Matemática.

Em 2010, participei do processo de seleção e, depois de aprovado, no mesmo ano, fui nomeado para o Departamento de Ciências Humanas do campus IX, Barreiras. Aquela mesma inquietude e medo de não estar preparado me acompanhava. Sentia que precisava estudar mais e me envolver muito. Penso que eram essas inseguranças, comuns na/da docência, que me faziam (re)pensar a minha formação e (re)significar a minha prática. Fui me ajustando, diariamente, aos novos desafios impostos pela carreira do magistério superior.

$\mathrm{Na}$ Universidade, realizei algumas atividades de pesquisa e extensão, sempre com o envolvimento dos estudantes e professores da Educação Básica, e pensando em seus processos formativos. Muitas delas garantiam a participação, com apresentação de trabalho, em inúmeros eventos da área de educação matemática.

Em meio a inúmeras atividades que eram desenvolvidas, surgiu o convite para coordenar o Pro-Letramento e, posteriormente, o PNAIC (Plano Nacional de Alfabetização na Idade Certa). O aceite rápido a esse convite me aproximou dos professores que ensinam matemática nos anos iniciais do ensino fundamental, uma vez que era responsável por pensar e acompanhar as formações dos formadores.

Claro que, antes disso, já tinha tido contato com o público dos anos iniciais, principalmente quando trabalhei com o curso de Pedagogia. No entanto, esses programas de formação me aproximaram do "chão da sala de aula" e das muitas vezes difíceis realidades que os professores que ensinam matemática nos anos iniciais [ainda] enfrentam. Lembro-me, quando trabalhamos o caderno de Frações no Pro-Letramento, o entusiasmo dos professores por estarem aprendendo algo que muitos confidenciavam não saber para ensinar.

Após dois anos de trabalho na Uneb, realizando atividades de ensino, pesquisa e extensão, resolvi fazer o mestrado em Educação, na linha de educação matemática. Optei por cursar na Universidade de Brasília (UnB), primeiramente por ser relativamente perto da cidade em que morava, já que precisaria viajar todas as semanas para fazer as disciplinas (uma vez que estava em estágio probatório e impossibilitado de afastar-me das atividades docentes) e pelo reconhecimento que a instituição tem na discussão de ludicidade e educação matemática. 
$\mathrm{Na}$ UnB participei da criação do grupo de pesquisa, Aprendizagem Lúdica: Pesquisas e Intervenções em Educação e Desporto (CNPq/UnB), coordenado por Antonio Villar Marques de Sá, meu orientador de mestrado, e amadureci muito, teoricamente falando, quanto às questões de pesquisa, e também ao reconhecer as diferentes perspectivas (sociológicas, filosóficas, psicológicas e educacionais, por exemplo) que tratam da ludicidade. Foi a partir de minha participação no grupo que surgiu o convite para organização de um livro, produto das pesquisas realizadas pelo grupo de pesquisa. O livro "Ludicidade e suas Interfaces", publicado em 2013 pela editora Liber Livros, foi um marco importante para minha trajetória acadêmico- profissional, e que permitiu aos leitores o contato com mais uma produção na área, algo não muito fácil de encontrar.

No doutoramento, iniciado em 2015 na Universidade Federal de São Carlos (UFSCar), dá-se continuidade aos trabalhos iniciados há anos com a minha formação e práticas profissionais: a preocupação com a formação, agora, dos que ensinam matemática nos anos iniciais.

\section{A Chegada ao Puzzle de Pesquisa}

Durante minha trajetória pessoal e profissional, como apresentado ao longo desta seção, me envolvi profundamente com as questões de ludicidade e formação de professores que ensinam matemática. Sempre, diante das atividades de ensino, pesquisa e extensão oferecidas, principalmente as que reuniam estudantes de Pedagogia e professores que ensinam matemática nos anos iniciais juntamente com os professores e estudantes de matemática dos demais segmentos, ouvia-se questionamentos e embates do tipo: "os estudantes não aprendem matemática nos anos finais, porque não foi apresentado como deveria essa ciência nos anos iniciais"; "como eu vou fazer os alunos gostarem e aprenderem matemática se eu mesmo não sei e não gosto?"; e "a ludicidade é o jogo, quando ele 'tá' presente a aula é lúdica”. Esses comentários eram frequentes, também, nos estágios que acompanhei.

Nessa direção, desafiado pelos questionamentos apresentados, resolvi trabalhar com a formação de professores dos anos iniciais no curso de Pedagogia, ministrando a disciplina de "Fundamentos Teórico e Metodológico do Ensino da Matemática". Era comum, por parte dos licenciandos, trazerem a representação de uma matemática complicada e desconectada das situações cotidianas, o que dificultava o trabalho enquanto formador e construção do conhecimento matemático por eles; algo preocupante, já que eles ensinariam futuramente esses conteúdos.

Foi na tentativa de identificar essas representações que os futuros professores têm da matemática e (re)significá-las a partir do uso de materiais com potencial lúdico, que percebi como a ludicidade pode contribuir muito positivamente para a formação e construção do conhecimento matemático pelos licenciandos. Essa experiência mais uma vez reforçava, em mim, a ideia de que o jogo e a brincadeira, bem como outras manifestações lúdicas, não são exclusivas para crianças. Os futuros professores (re)significam impressões que tiveram e aprendem, também, no momento do brincar. É preciso possibilitar isso a eles.

Pensando dessa forma, portanto, chego ao doutoramento e me aproximo da perspectiva de pesquisa narrativa. Pensá-la como a melhor forma de explicar e entender a experiência me possibilitou construir uma relação com as participantes em busca de ampliar o olhar acerca de questões que nos inquietavam.

\section{Algumas Considerações}

Nesse artigo apresentei um recorte de minha história de vida e estabeleci conexões entre minhas experiências, de vida e profissional, e o meu puzzle de pesquisa. Essa seção surge a partir do que é posto por Clandinin e Connelly (2015) de que a pesquisa narrativa começa com a narrativa do pesquisador orientada autobiograficamente. E foi isso justamente o que fiz: um 
resgate de minha história de vida e um estabelecer relações entre o que aponto teoricamente, ao longo do trabalho, com o que vivenciei ao longo de minha trajetória de vida.

Nesse processo de rememoração e de recontar as minhas trajetórias, de vida e profissional, percebi a possibilidade de estabelecer algumas conexões teóricas com que narrei dessas experiências. Algumas delas envoltas a percepção da formação de professores como um campo de estudo complexo, como defendem André (2010), Roldão (2007) e Flores (2014) e outras, que se referem a minha aproximação, desde a infância, com as questões voltadas a ludicidade e a repercussão disso para a minha futura prática profissional e estabelecimento do puzzle de pesquisa.

Isso, que aponto anteriormente, me fez questionar os conhecimentos necessários para a atividade docente e o perceber que elas não se reúnem apenas durante uma formação inicial ou continuada. Para isso, levei em consideração o que é apontado por André (2010, p. 175) e Oliveira (2011) de que é importante dar atenção às representações, crenças, preconceitos dos docentes, pois elas vão afetar sua aprendizagem da docência e possibilitar ou dificultar mudanças. Em relação às questões voltadas a ludicidade, por exemplo, percebi que, como aponta Alves (2012), a forma como via os jogos e as brincadeiras, imagem construída ainda na infância, foi importante no processo de utilização dessas ferramentas.

Nessa direção, portanto, corroborei ao que destaca André (2010), de que é preciso pensar a formação docente como resultado de aprendizagens que acontecem ao longo da vida e acrescentei que a formação é marcada tanto pelo que aconteceu antes do seu início, bem como é vulnerável dos percalços do processo. Para isso, portanto, fiz uma relação entre o apresentado e a experiência com o curso de Matemática feito por mim até 2008. Preocupar-se com os currículos dos cursos de formação inicial é algo legítimo e importante, porque, de acordo com Zeichner e Gore (1990, apud FLORES, 2014, p. 219), "a influência socializadora da formação inicial depende da natureza, do modelo e da estrutura do curso de formação, mas também das crenças e das perspectivas pessoais que os alunos trazem consigo".

Dessas experiências fui estabelecendo as relações entre minha história de vida e meu puzzle de pesquisa. Para isso, sobretudo, destaquei a importância que a minha chegada como professor a Universidade teve. Envolvido com a coordenação do Laboratório de Educação Matemática, o Pro-Letramento e o PNAIC, nasceu meu problema de pesquisa para o mestrado e, em seguida, o do doutorado. Durante toda minha trajetória pessoal e profissional, como foi apresentado ao longo desta seção, me envolvi profundamente com as questões de ludicidade e formação de professores que ensinam(arão) matemática. Este trabalho abre espaço para que outras pesquisas sejam construídas, sobretudo pensando o lugar das narrativas no movimento de formação de professores.

\section{Referências}

Alves, E. M. S. (2012) A ludicidade e o ensino da matemática: uma prática possível. (7a ed.): Papirus.

André, M. (2010). Formação de professores: a constituição de um campo de estudos. Educação, 174-181.

Benjamin, W. (1996). Experiência e Pobreza. In: Benjamin, W. Magia e Técnica, Arte e Política. Tradução de Sérgio Paulo Rouanet: Brasiliense.

Caporale, S. M. D. (2016). Escrever e compartilhar histórias de vida como práticas de (auto) formação de futuros professores e professoras de matemática. 241 p. Tese (Doutorado em Educação). Programa de Pós-Graduação Stricto Sensu em Educação. Universidade São Francisco, Itatiba/SP.

Cerrillo, Q. M.-M. (2001). La escuela como espacio de trabajo para los profesores. In: Marcelo, C. La función docente: Editorial Síntesis. 141-170.

Clandinin, D. J., \& Connelly, F. M. (2000). Narrative inquiry: experience and story in qualitative research: Jossey-Bass.

Clandinin, D. J. (2013). Engaging in narrative inquiry: Left Coast Press.

Clandinin, D. J., \& Connelly, F. M. (2015). Pesquisa Narrativa: Experiência e História em Pesquisa Qualitativa: EDUFU.

Cunha, R. B. (2007). Lembranças de escola na formação inicial de professores. In: Prado, G. D. V. T., \& Cunha, R. B. Percursos de autoria: exercícios de pesquisa: Alínea, p. 97-112.

D'Ambrosio, U. (1998). Etnomatemática: Arte ou técnica de explicar ou conhecer. (5a ed.): Ática. 
Day, C. (2014). A resiliência, os professores e a qualidade da Educação. In: Flores, M. A., \& Coutinho, C. Formação e trabalho docente: diversidade e convergências: De Facto.

Flores, M. A. (2010). Algumas reflexões em torno da formação inicial de professores. Educação.

Flores, M. A. (2014). Formação e Desenvolvimento profissional de professores: contributos internacionais: Almedina.

Gatti, B. (2010). Formação de professores no Brasil: características e problemas. Educação e Sociedade. 1355-1379.

Guedes-Pinto, A. L. (2012). Memorial de Formação: Registro de um percurso. Faculdade de Educação da Unicamp, Campinas.

Josso, M. C. (2007). A transformação de si a partir da narração de histórias de vida, 3(63), 413-438.

Kenski, V. M. (1996). Memória prática docente. In: Brandão, C. R. As Faces da Memória: Centro de Memória- Unicamp.

Knijnik, G. (1997). As novas modalidades de exclusão social: trabalho, conhecimento e educação. Revista Brasileira de Educação.

Larrosa Bondía, J. (2002). Notas sobre a experiência e o saber de experiência. Revista Brasileira de Educação, 21-28.

Libâneo, J. C. (2007). Pedagogia e pedagogos para que? (9a ed.): Cortez.

Loughran, J. (2009). A construção do conhecimento e o aprender a ensinar sobre o ensino. In: Aprendizagem e desenvolvimento profissional de professores: contextos e perspectivas. Mangualde: Edições Pedago, 17-37.

Marcelo Garcia, C. (2009). Desenvolvimento profissional: passado e futuro. Sísifo - Revista das Ciências da Educação.

Oliveira, R. M. M. A. (2011). Narrativas: contribuições para a formação de professores, para as práticas pedagógicas e para a pesquisa em educação. Educução Pública, Cuiabá, maio/agosto. 289-305.

Linhares, C. F. S. (2008). Trabalhadores sem trabalho e seus professores: Um desafio para a formação docente. In: Alves, N. Formação de professores: pensar e fazer: Cortez, v. 1.

Passos, C. L. B. (2010). Materiais manipuláveis como recursos didáticos na formação de professores de Matemática. In: Lorenzato, S. O laboratório de ensino de Matemática na formação de professores. (2a ed.): Autores Associados, 77-92.

Roldão, M. D. C. (2007). A formação de professores como objecto de pesquisa - contributos para a construção do campo de estudo a partir de pesquisas portuguesas. Revista Eletrônica de Educação, São Carlos, setembro, 50-108.

Silva, A. J. N. (2016). Querido Diário: O Que Dizem As Narrativas Sobre A Formação E A Futura Prática Do Professor Que Ensinará Matemática Nos Anos Iniciais. Revista Brasileira de História, Educação e Matemática (Hipátia), Campos do Jordão(SP), 1(1), 46-57.

Silva, A. J. N., \& Passos, C. B. (2019). Conhecendo mais sobre a ludicidade, formação de professores e ensino de matemática no curso de pedagogia da UFSCAR. Revista Brasileira De Pesquisa (Auto)biográfica, 4(10), 264-282.

Silva, A. J. N., \& Passos, C. L. B. (2020). Formação do professor que ensina matemática, ludicidade e narrativas: o que se pesquisou no Brasil. Revista Eletrônica de Educação, 14, jan./dez, e3631066, 1-18.

Silva, A. J. N. (2020a). Ensinar matemática nos anos iniciais e ludicidade: o que significou para estudantes de uma turma do curso de pedagogia da UFSCar? Educação Online Puc-RJ, 15(35), 157-175.

Silva, A. J. N. (2020b). O curso de Pedagogia e a formação de educadoras matemáticas: o que revelam narrativas de um encontro de formação? In: Gestão educacional e formação docente. Pembroke Collins, 1, 13-29.

Silva, A. J. N. (2020c). Pesquisa Narrativa: Por Que Não Tive Contato Com Essa Perspectiva De Investigação Antes E Quais Motivos Me Fizeram EscolheLa? In: Celso Gabatz; Danielle Ferreira Medeiro da Silva de Araújo; Giovanni Codeça da Silva; Walkyria Chagas da Silva Santos. (Org.). Perspectivas contemporâneas de educação. Pembroke Collins, 3, 157-172.

Souza, E. C. (2006). A arte de contar e trocar experiências: Reflexões teórico-metodológicas sobre história de vida em formação. Revista Educação em Questão, 22-39. 